\title{
Magnetron Sputtering Silicon Thin Film Electrodes for Lithium-Ion Batteries
}

\author{
E. Evshchik ${ }^{1, *}$, D. Novikov ${ }^{2}$, A. Levchenko ${ }^{1,2}$, S. Nefedkin ${ }^{3}$, A.V. Shikhovtseva ${ }^{1}$, \\ O.V. Bushkova ${ }^{1,2,4}$ Yu. A. Dobrovolsky ${ }^{l}$ \\ ${ }^{1}$ Institute of Problems of Chemical Physics of Russian Academy of Sciences, pr. akad. Semenova 1, \\ Chernogolovka, Russia \\ ${ }^{2}$ Inenergy LLC, Elektrodnajast. 12, Bld. 1, Moscow, Russia \\ ${ }^{3}$ MEI National Research University, 14, Krasnokazarmennaya, Moscow, Russia \\ ${ }^{4}$ Institute of Solid State Chemistry, Ural Branch of the Russian Academy of Sciences, Pervomaiskaya \\ st. 91, Ekaterinburg, Russia \\ EE-mail: liza@icp.ac.ru
}

doi: $10.20964 / 2018.03 .05$

Received: 23 October 2017 / Accepted: 19 December 2017 / Published: 5 February 2018

Thin silicon films were deposited on surface-modified copper foil by magnetron sputtering; Si mass loading varied from 0.013 to $0.400 \mathrm{mg} / \mathrm{cm}$. Scanning electron microscopy (SEM), X-ray photoelectron spectroscopy (XPS), X-ray diffraction (XRD), and transmission electron microscopy (TEM) were used to characterize the structure, morphology, and composition of the Si films as a function of mass loading. It was established that $\mathrm{Si}$ films repeated the hill-like morphology of $\mathrm{Cu}$ foil surface and consisted of nearly spherical agglomerates of amorphous silicon; the average size and packing of agglomerates varied as the $\mathrm{Si}$ mass loading changed. Galvanostatic half-cell electrochemical measurements were carried out within the range of 0.04-2.0 V with a lithium foil as the counter electrode and $1 \mathrm{M}$ solution of $\mathrm{LiPF}_{6}$ in 1:1 (v/v) mixture of ethylene carbonate (EC) and diethyl carbonate (DEC) as the electrolyte. According to the results obtained, the highest value of the reversible capacity of about $1200 \mathrm{mAh} / \mathrm{g}$ after 50 charge-discharge cycles at $0.1 C$ was observed in the electrodes with a Si mass loading of $0.293 \mathrm{mg} / \mathrm{cm}$. The non-monotonic dependence of the reversible capacity $v s$. Si mass loading is likely to be caused by the structural evolution of the amorphous Si thin films.

Keywords: Li-ion batteries, Silicon electrode, Thin film, Magnetron sputtering, Morphology, Cycling performance

\section{FULL TEXT}


(C) 2018 The Authors. Published by ESG (www.electrochemsci.org). This article is an open access article distributed under the terms and conditions of the Creative Commons Attribution license (http://creativecommons.org/licenses/by/4.0/). 